\title{
The utilization of aerosol therapy in mechanical ventilation patients: a prospective multicenter observational cohort study and a review of the current evidence
}

\author{
Shan Lyu ${ }^{1 \#}$, Jie $\mathrm{Li}^{2 \#}$, Limin Yang ${ }^{3}$, Xiaoliang $\mathrm{Du}^{4}$, Xiaoyi Liu ${ }^{5}$, Libo Chuan ${ }^{6}$, Guoqiang Jing ${ }^{7}$, Zhenyan Wang, \\ Weiwei Shu ${ }^{9}$, Chunjuan Ye ${ }^{10}$, Qionglan Dong ${ }^{11}$, Jun Duan ${ }^{12}$, James B. Fink ${ }^{2,13}$, Zhancheng Gao ${ }^{14}$, \\ Zongan Liang $^{15}$; on behalf of Respiratory Care Committee in Chinese Thoracic Society
}

${ }^{1}$ Department of Critical Care Medicine, Peking University People's Hospital, Beijing, China; ${ }^{2}$ Department of Cardiopulmonary Sciences, Division of Respiratory Care, Rush University Medical Center, Chicago, IL, USA; ${ }^{3}$ Department of Respiratory Care, Zhejiang University School of Medical Sir Run Run Shaw Hospital, Hangzhou, China; ${ }^{4}$ Department of Neurosurgical, Tongji Medical College of Huazhong University of Science and Technology Tongji Hospital, Wuhan, China; ${ }^{5}$ Department of Critical Care Medicine, Dazhou Central Hospital, Dazhou, China; ${ }^{6}$ Intensive Care Unit, the First People's Hospital of Yunnan Province, Kunming, China; ${ }^{7}$ Department of Respiratory and Critical Care Medicine, Binzhou Medical University Hospital, Binzhou, China; ${ }^{8}$ Department of Critical Care Medicine, Peking University International Hospital, Beijing, China; ${ }^{9}$ Department of Critical Care Medicine, Yongchuan Hospital of Chongqing Medical University, Chongqing, China; ${ }^{10}$ Department of Surgical Intensive Care Unit, the First Affiliated Hospital of Xi'an Jiaotong University, Xi'an, China; ${ }^{11}$ Department of Critical Care Medicine, the Third People's Hospital of Mianyang, Mianyang, China; ${ }^{12}$ Department of Respiratory and Critical Care Medicine, the First Affiliated Hospital of Chongqing Medical University, Chongqing, China; ${ }^{13}$ Aerogen Pharma Corp, San Mateo, CA, USA; ${ }^{14}$ Department of Respiratory and Critical Care Medicine, Peking University People's Hospital, Beijing, China; ${ }^{15}$ Department of Respiratory and Critical Care Medicine, West China Medical Center, Sichuan University, Chengdu, China

Contributions: (I) Conception and design: S Lyu, J Li, Z Gao, Z Liang; (II) Administrative support: Z Gao, Z Liang; (III) Provision of study materials or patients: S Lyu, L Yang, X Du, X Liu, L Chuan, G Jing, Z Wang, W Shu, C Ye, Q Dong, J Duan; (IV) Collection and assembly of data: S Lyu; (V) Data analysis and interpretation: S Lyu, J Li; (VI) Manuscript writing: All authors; (VII) Final approval of manuscript: All authors.

\#These authors contributed equally to this work.

Correspondence to: Prof. Zongan Liang. Department of Respiratory and Critical Care Medicine, West China Medical Center, Sichuan University, 37 Guo Xue Street, Chengdu, China. Email: liang.zongan@163.com; Prof. Zhancheng Gao. Department of Respiratory and Critical Care Medicine, Peking University People's Hospital, No. 11 Xizhimen Nandajie Beijing, China. Email: zcgao@bjmu.edu.cn.

Background: Aerosol delivery via mechanical ventilation has been reported to vary significantly among different intensive care units (ICU). The optimal technique for using each aerosol generator may need to be updated with the available evidence.

Methods: A 2-week prospective multicenter observational cohort study was implemented to record aerosol delivery for mechanically ventilated adult patients in Chinese ICUs. Our data included the type of aerosol device and its placement, ventilator type, humidification, and aerosolized medication administered. A guide for the optimal technique for aerosol delivery during mechanical ventilation was summarized after a thorough literature review.

Results: A total of 160 patients (105 males) from 28 ICUs were enrolled, of whom 125 (78.1\%) received aerosol therapy via invasive ventilation. Among these 125 patients, 53 received ventilator-integrated jet nebulizer, with $64 \%$ (34/53) of them placed the nebulizer close to Y piece in the inspiratory limb. Further, 56 patients used continuous nebulizers, with $84 \%$ (47/56) of them placed the nebulizer close to the Y piece in the inspiratory limb. Of the 35 patients who received aerosol therapy via noninvasive ventilation, 30 received single limb ventilators and continuous nebulizers, with $70 \%(21 / 30)$ of them placed between the mask and exhalation port. Only $36 \%(58 / 160)$ of the patients received aerosol treatments consistent with optimal practice.

Conclusions: Aerosol delivery via mechanical ventilation varied between ICUs, and only $36 \%$ of the 
patients received aerosol treatments consistent with optimal practice. ICU clinicians should be educated on the best practices for aerosol therapy, and quality improvement projects aim to improve the quality and outcome of patients with the optimal technique for aerosol delivery during mechanical ventilation are warranted.

Keywords: Inhalation therapy; mechanical ventilation; a follow-up study

Submitted Feb 04, 2020. Accepted for publication Jul 24, 2020.

doi: 10.21037/atm-20-1313

View this article at: http://dx.doi.org/10.21037/atm-20-1313

\section{Introduction}

Aerosol therapy delivers medications directly into the lung. Aerosol therapy has many advantages compared with systemic administration, including targeted delivery into the lung, faster response, and fewer systemic adverse effects (1). These differences have resulted in the broad use of aerosol therapy in intensive care units (ICUs) $(2,3)$. A considerable proportion of ICU patients require artificial airway and mechanical ventilation, unlike outpatient or general unit patients, which introduces more factors that impact aerosol deposition, including the types of aerosol generator (4-6), the position of the aerosol generator in the ventilator circuit $(5,7,8)$, mechanical ventilation settings (8-11), humidification (4,11-13), reservoirs (14-16), and inspiratory synchronization of aerosol generation (17-20). Substantial efforts have been made to understand these variables and to improve the efficiency of aerosol delivery to the lungs and minimize loss, including aerosol deposition in the ventilator circuits and artificial airways $(21,22)$.

In 2011, Ehrmann et al. (23) conducted an international survey with 1,192 responses from 70 countries on aerosol therapy during mechanical ventilation. Aerosol therapy was found to vary in different institutions, and a knowledge gap among clinicians about how to administer aerosol delivery via mechanical ventilation was discovered. However, with fewer than $9 \%$ of the participants reporting from Asia (23), detailed information about Chinese ICUs remains mostly unknown. In 2014, Zhu et al. conducted a nationwide survey on aerosol therapy in mainland China, but their focus was on spontaneously breathing patients rather than mechanically ventilated patients (24). They found a considerable proportion of physicians and nurses who specialized in pulmonary and critical care medicine lacked knowledge on the correct use of different inhalers. As such, the Respiratory Care Committee in the Chinese Thoracic Society published two consensus documents to guide clinicians for optimizing aerosol therapy for spontaneously breathing patients (25) and for mechanically ventilated patients (26). Last year, Zhang et al. (27) carried out an online survey of Chinese respiratory care practitioners and found substantial heterogeneity among institutions, and many practices not following the consensus. However, these findings need to be cautiously interpreted due to participants' recall bias. The clinical practice of aerosol therapy for Chinese ICU patients, reported in real time, is still unknown.

In the 2-week cross-sectional study conducted by Ehrmann et al. (28), it was found that the findings from aerosol studies were not consistently translated into clinical practice. The participating centers were predominantly located in Europe (65 of 81), with only 4 Asian ICUs in the study. To compare with the clinical practices of international peers, we translated the data collection form used by Ehrmann (with permission). The objective of this study was to identify the current practices of aerosol therapy for mechanically ventilated patients in Chinese ICUs and to recognize the gaps between clinical practice and actual practice using the best evidence. Moreover, we sought the current optimal evidence (Tables S1-S3) of aerosol delivery via mechanical ventilation to summarize the recommendations (Tables 1,2), to help update the consensus in the next steps. This article is presented following the STROBE reporting checklist (available at http://dx.doi. org/10.21037/atm-20-1313).

\section{Methods}

This study is a prospective multicenter observational cohort study. It was registered on ClinicalTrials.gov (NCT03597334) and was conducted by the Respiratory Care Committee of the Chinese Thoracic Society. Recruitment advertisement was posted on the official social 
Table 1 The optimal placement of jet nebulizer, vibrating mesh nebulizer and pMDI during invasive and noninvasive ventilation

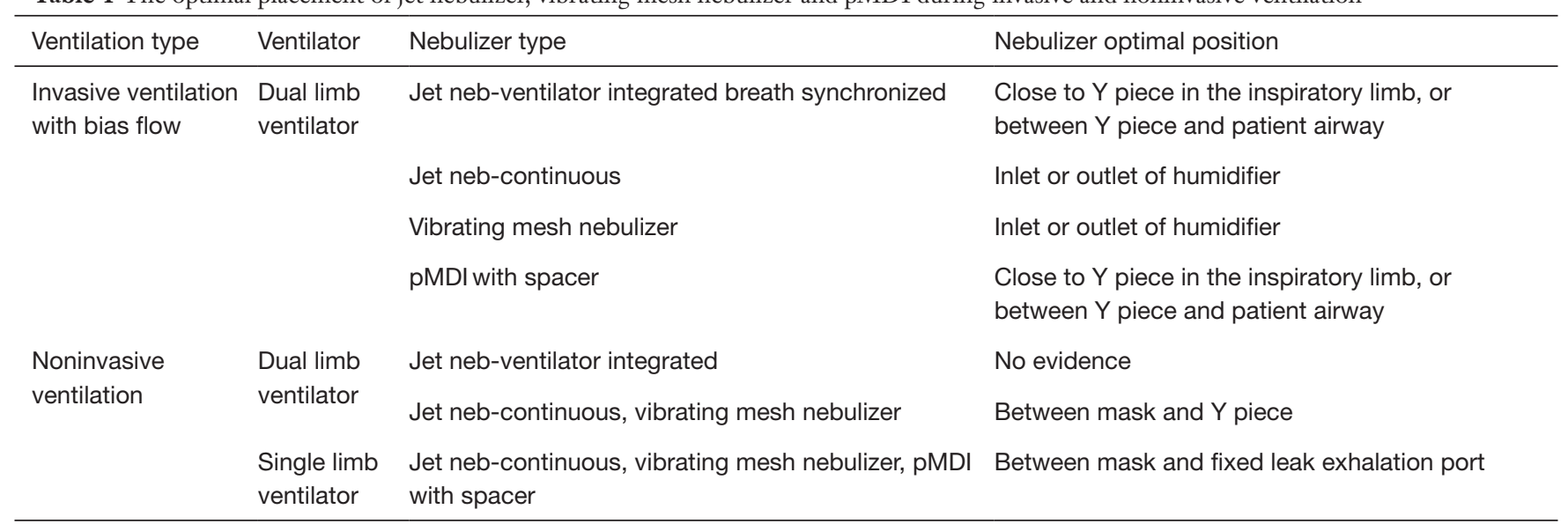

neb, nebulizer; pMDI, pressurized metered dose inhaler.

Table 2 Optimal practice of using pMDI, humidification and expiratory filter during aerosol therapy

\begin{tabular}{ll}
\hline Practice & Optimal practice \\
\hline $\begin{array}{l}\text { Use of pMDI } \\
\text { Humidification }\end{array}$ & Combined use of spacer \\
Active humidifier & Do not turn it off for aerosol administration \\
HME & $\begin{array}{l}\text { Remove from between neb and patient } \\
\text { during aerosol treatment }\end{array}$ \\
Expiratory filter & $\begin{array}{l}\text { Should be in the expiratory limb during } \\
\text { aerosol treatment } \\
\end{array}$ \\
& $\begin{array}{l}\text { Monitor expiratory resistance and change } \\
\text { the filter as needed }\end{array}$ \\
\hline
\end{tabular}

pMDI, pressurized metered dose inhaler; HME, heat moisture exchanger.

media (WeChat App, Tencent, Hangzhou, China) of the Respiratory Care Committee of the Chinese Thoracic Society and centers were enrolled voluntarily. The study was conducted in accordance with the Declaration of Helsinki (as revised in 2013). The study was approved by the ethics committee of the leading hospital (Peking University People's Hospital, IRB approval No. 2018PHB058$01)$. Additional ethical approvals were gained at each participating institution if required by the participating hospital. Written informed consent was obtained from patients or legal surrogates in all participating ICUs.

All adult patients who aged 18 and above and stayed in ICU between midnight on July 9, 2018, and midnight on July 23, 2018, who received invasive or noninvasive ventilation and agreed to participate in this study were eligible for inclusion. Patients were excluded if they were placed on palliative care. Each patient was observed for up to 28 days or until discharge from ICU. All patients in each ICU were registered, and identification information was recorded to allow for verification by the primary investigator to avoid any patient enrollment bias or patients being missed. The primary endpoint was to identify the proportion of patients receiving aerosol treatments consistent with optimal practice. The secondary endpoints were to identify mechanically ventilated patients receiving aerosol therapy and to investigate aerosol therapy practice and side effects in various ICUs. Respiratory support, prescribed aerosol therapy (aerosol generator and placement), and adverse events were recorded for each patient daily along with the patients' demographic information. The optimal delivery guide (Tables 1,2) was used to assess if each patient received optimal therapy or not.

Normal distribution quantitative variables were expressed as the mean \pm standard deviation and compared with Student's $t$-test, and non-normal distribution quantitative variables were expressed as the median (interquartile) and compared using the Mann Whitney test. Qualitative variables were expressed as counts (\%) and compared between the groups using the chi-square test. A 95\% confidence interval (95\% CI) of proportions was calculated for the main variables of aerosol therapy. Missing data were also reported in the results. A $\mathrm{P}$ value of less than 0.05 was considered significant. Data analysis was performed using SPSS (SPSS 23.0, Chicago, IL, USA). 


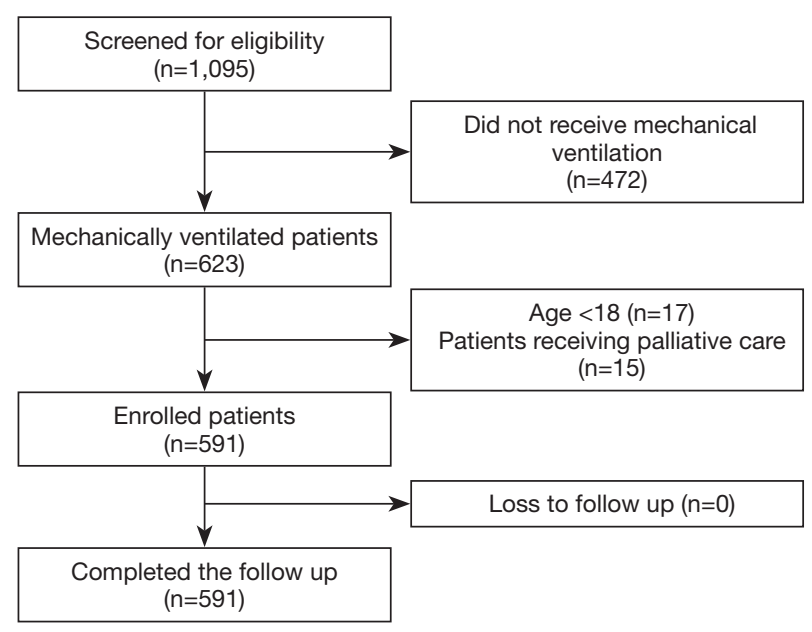

Figure 1 Flow chart.

\section{Results}

This study was carried out with respondents representing 28 ICUs from 28 hospitals in mainland China (the centers and investigators are listed in the Appendix 1); 27 (96.4\%) were teaching hospitals. The number of beds in the participating ICUs and hospitals was $20 \pm 13.2$ and 2,266.1 $\pm 1,299.6$, respectively. During the study period (Figure 1), 1,066 patients were screened in the ICUs, with 507 patients excluded due to the following reasons: 472 patients did not receive mechanical ventilation, 17 patients were aged under 18 years old, and 15 patients were placed on palliative care. Eventually, 591 patients receiving mechanical ventilation were enrolled. These 591 patients completed follow-ups and were analyzed. The median follow-up time for each patient was 5 days; the maximum follow-up time was 28 days. Data were complete for all 591 patients, of whom 160 (27.1\%; 95\% CI: $23.5-30.7 \%$ ) received 4,198 aerosol treatments while in the ICU. Among the 160 patients, 125 received invasive ventilation, and 35 patients received noninvasive ventilation. Only six patients were ordered to change from aerosolized medications during the study period.

Of the 160 patients receiving aerosol therapy, the mean age was $68.0 \pm 15.6$ years, and $65.6 \%(105 / 160)$ of the patients were male. The majority $(76.9 \%, 123 / 160)$ of the patients were non-surgical, and $56.3 \%(90 / 160)$ had cardiopulmonary diseases. The average Sequential Organ Failure Assessment (SOFA) score of these 160 patients, when admitted to ICU, was $5.5 \pm 2.6$. The median length of ICU stay for these patients was 8 days. During the study period, $57.5 \%(92 / 160)$ of the patients were transferred to general units, $21.9 \%(35 / 160)$ of them were discharged, $11.3 \%(18 / 160)$ of them remained in ICU after 28 days, and 9.4\% (15/160) died.

The 160 patients who received aerosol therapy were older $(68.0 \pm 15.6$ vs. $60.0 \pm 16.8$ years, $\mathrm{P}<0.001)$ and had more cardiopulmonary comorbidities $(55.4 \%$ vs. $26.5 \%$, $\mathrm{P}<0.001$ ), and a higher percentage of them were diagnosed with acute respiratory failure or acute exacerbation of chronic respiratory failure $(45.8 \%$ vs. $16.1 \%, \mathrm{P}<0.001)$, compared with the 431 patients who did not receive aerosol therapy. In the 28-day outcomes, patients who received aerosol therapy had a longer ICU stay $\{8[4,14]$ days vs. $4[2,10]$ days, $\mathrm{P}<0.001\}$ \{median [interquartile]\}, longer invasive ventilation duration $\{4[1,9]$ days $v s .2[1,4]$ days, $\mathrm{p}=0.007\}$ \{median [interquartile] $\}$, longer noninvasive ventilation duration $\{0[0$, $3]$ days vs. $0[0,0]$ days, $\mathrm{P}<0.001\}$ \{median [interquartile]\}, and a higher percentage of them were discharged against medical advice $(20.8 \%$ vs. $9.5 \%, \mathrm{P}<0.001)$, compared with patients who did not receive aerosol therapy.

\section{Aerosol therapy practice during invasive ventilation}

All patients receiving at least one aerosol treatment were on ventilators with bias flow settings during invasive ventilation. The most commonly utilized aerosol generator was the pneumatic jet nebulizer, which was used in $67.2 \%(84 / 125)$ of the patients, followed by a vibrating mesh nebulizer (15.2\%), a metered-dose inhaler (MDI) (12.8\%), and an ultrasonic nebulizer (4.8\%). For the pneumatic jet nebulizers, $63.1 \%$ $(53 / 84)$ of the individuals were driven by the ventilator to generate aerosol synchronized with inspiration (breathsynchronized nebulizer) (Table 3), and 64.2\% (34/53) were placed close to the $\mathrm{Y}$ piece on the inspiratory limb. The remaining 31 individuals on the jet nebulizers were powered by an external compressed gas source operated continuously (continuous nebulizer), with $71 \%$ (22/31) of them placed close to the $\mathrm{Y}$ piece in the inspiratory limb, and $12.9 \%$ (4/31) being placed $20-30 \mathrm{~cm}$ away from the $\mathrm{Y}$ piece in the inspiratory limb. The vibrating mesh nebulizer and ultrasonic nebulizer were both placed close to the $\mathrm{Y}$ piece in the inspiratory limb (Figure 2) for patients receiving aerosol with MDI. Among patients who used an MDI $(\mathrm{n}=18)$, only 1 (5.6\%) patient used a spacer chamber.

No ventilator modes were changed during aerosol therapy. Ventilator parameters were changed in 8 (6.4\%) invasively ventilated patients, with decreasing inspiratory flow $(\mathrm{n}=3,2.4 \%)$ and increasing inspiratory trigger 
Table 3 Aerosol generator and its placement in the ventilator circuit during mechanical ventilation

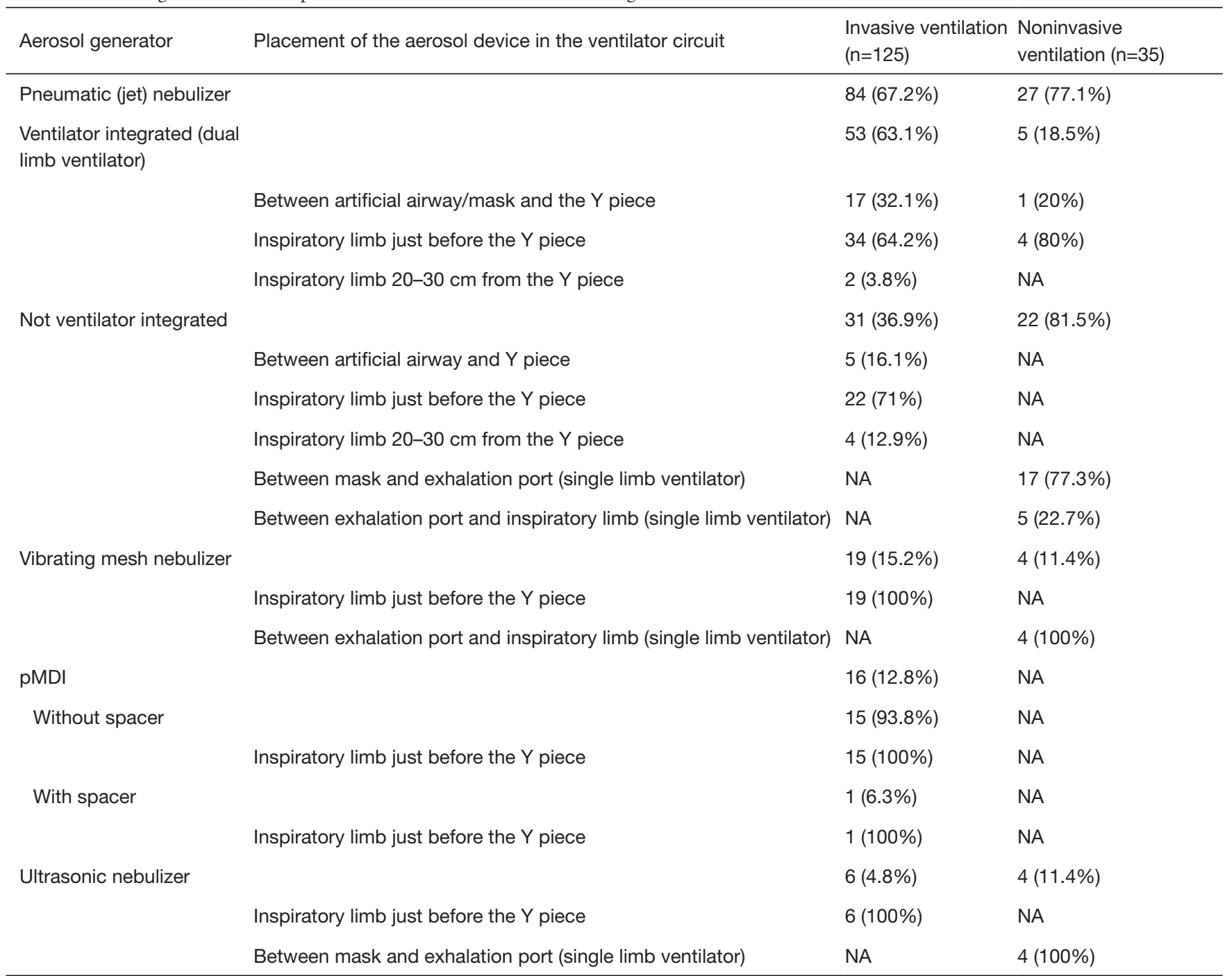

pMDI, pressurized metered dose inhaler.

sensitivity $(\mathrm{n}=2,1.6 \%)$ being the main adjustments, while $75 \%(6 / 8)$ used breath-synchronized nebulizer.

During aerosol therapy, 110 of 125 (88\%) of the patients used active humidifiers, with $9(8.2 \%)$ turned off humidifiers . Fifteen patients used heat moisture exchangers (HME), with only $26.7 \%$ of the patients (4/15) having HME removed during aerosol therapy. During invasive ventilation, $54.4 \%(68 / 125)$ of the patients did not have a filter placed on the expiratory port.

\section{Aerosol therapy practice during noninvasive ventilation}

Among the 81 patients on noninvasive ventilation, 35 patients $(43.2 \%)$ received aerosol therapy. Among the 35 patients, jet nebulizer $(\mathrm{n}=27,77.1 \%)$ was the most common, while a vibrating mesh nebulizer and an ultrasonic nebulizer were used in $11.4 \%$ (4/35) and $11.4 \%$ (4/35) of the patients, respectively. Dual limb ventilators were used in $14.3 \%(5 / 35)$ of the patients, and all of them used ventilator-integrated jet nebulizers, with $80 \%(4 / 5)$ of them placed close to the $\mathrm{Y}$ piece in the inspiratory limb. Continuous jet nebulizers were used by $73.3 \%$ (22/30) of the remaining 30 patients who used single limb ventilators, with $77.3 \%(17 / 22)$ placed between the mask and exhalation port. Vibrating mesh nebulizers were used by $13.3 \%$ (4/30) of patients, and all of the nebulizers were placed between 

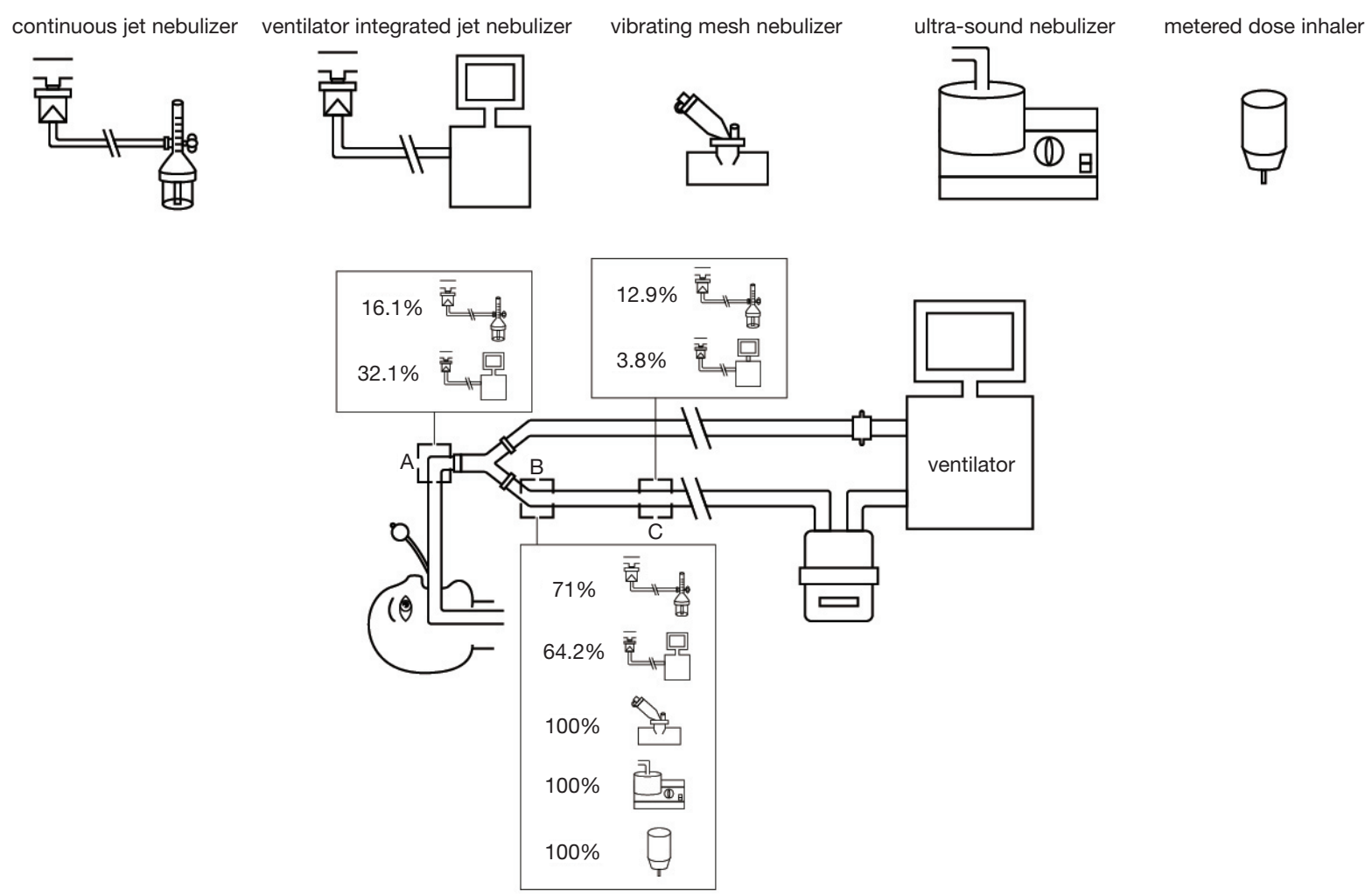

Position A: between artificial airway and the $Y$ piece

Position B: inspiratory limb just before the $Y$ piece

Position C: inspiratory limb 20-30 cm away from the $Y$ piece

Figure 2 The portions of aerosol generator placements during invasive ventilation.

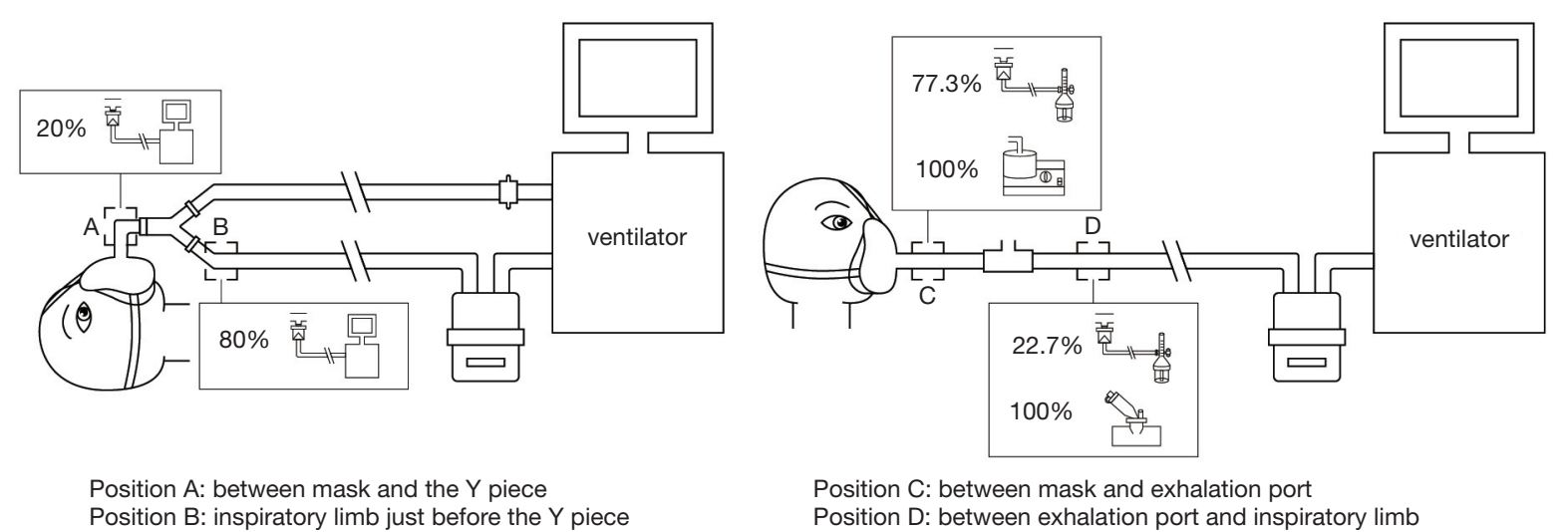

Figure 3 The portions of aerosol generator placements during noninvasive ventilation using dual limb and single limb ventilators.

the exhalation port and inspiratory limb (Figure 3). The ventilation mode was not changed for aerosol therapy. Only $14.3 \%(5 / 35)$ of the patients had increased trigger sensitivity.

\section{Short term safety of aerosol therapy}

No adverse effect of aerosol therapy was observed in $92 \%$ $(115 / 125)$ of the invasively ventilated patients and $85.7 \%$ 
(30/35) of the noninvasively ventilated patients. Among the patients who suffered adverse effects, a cough was the most common complication and was developed by $2.4 \%$ $(3 / 125)$ and $5.7 \%(2 / 35)$ of patients who received invasive ventilation and noninvasive ventilation, respectively. However, hypoxemia was found in one invasively ventilated patient and one noninvasively ventilated patient, and tachycardia was found in two invasively ventilated patients.

\section{Patients who received optimal aerosol delivery}

Using the guide from Tables 1 and 2, only 36.3\% (58/160) (95\% CI: $28.7-43.8 \%$ ) of patients received aerosol therapy under optimal practice, and the proportions of invasively and noninvasively ventilated patients were $29.6 \%(37 / 125)$ (95\% CI: $21.5-37.7 \%$ ) and 60.0\% (21/35) (95\% CI: 42.9$77.1 \%)$, respectively.

\section{Discussion}

\section{Nebulizer placement in the ventilator circuits}

Traditional pneumatic jet nebulizers generate aerosol continuously, resulting in a waste of aerosol during the exhalation phase (13), which is usually $2-3$ times longer than the inhalation phase. Additionally, when the continuous jet nebulizer is connected to the ventilator system, the extra compressed gas used to power the jet nebulizer affects the ventilator function (29), which may cause patient-ventilator asynchrony, air-trapping or even ventilator-associated lung injury (30). As such, some ventilator manufacturers integrate gas delivery ports to power jet nebulizers during inspiration to avoid or minimize the impact on the ventilator's function (17). Breath synchronization improves inhaled dosage compared to a continuous jet nebulizer, but only when the nebulizer is placed close to the Y-piece in the inspiratory limb of a dual limb ventilator during invasive ventilation (13).

In 2010, Ari et al. compared the placement of continuous jet nebulizers and vibrating mesh nebulizers during invasive ventilation with bias flow. They found that the inhaled dose with the nebulizer placed at the inlet of the humidifier was higher than that with the nebulizer placed close to the patient, regardless of the nebulizer type (7). Three years later, Berlinski et al. further confirmed this finding in their pediatric models, regardless of ventilator settings (5). Both researchers explained that the improvement was due to the reservoir effects of the humidifier chamber and inspiratory limb. Since then, continuous nebulizers have been recommended to be placed at the inlet or outlet of the humidifier while breath-synchronized jet nebulizers should be placed close to the $\mathrm{Y}$ piece in the inspiratory limb during invasive ventilation (22).

However, this rule does not apply for noninvasive ventilation. The inhaled dose was shown to be higher when both continuous jet and mesh nebulizers were placed between the mask and the $\mathrm{Y}$ piece than that with nebulizers placed at the inlet of the humidifier in a recent vitro study using a dual limb ventilator for pediatric manikin (31). No studies have investigated the placement of ventilatorintegrated jet nebulizer during noninvasive ventilation. Thus, its optimal placement in the dual limb ventilator is still unknown. When using a single limb circuit with a fixed leak for NIV with a turbine-type ventilator, in vitro studies in adult and pediatric models have confirmed that a continuous jet nebulizer, vibrating mesh nebulizer, and pMDI should be placed between the fixed leak exhalation port and the patient $(8,32-34)$.

The most common error in our observation was the placement of continuous nebulizers (including jet, mesh, and ultrasonic nebulizers) during invasive ventilation with a biased flow setting. None of the participants placed the continuous nebulizers at correct locations in the inspiratory limb of the circuit. This is problematic because the aerosol generated in the exhalation phase could be collected in the humidifier or inspiratory limb, which serves as a reservoir, increasing the inhaled dose available to the patient.

During NIV, the optimal position for the stabilizing nebulizer is an upright operating position, which can present challenges. For example, the placement of the jet or mesh nebulizer between the fixed exhalation port and patient mask in the single limb ventilator. Modifications on some noninvasive ventilation masks that allow for the nebulizer to be directly placed on the mask might help to resolve this dilemma $(31,34,35)$. However, this type of mask has not been broadly utilized yet, and follow-up studies are warranted to determine its clinical efficacy.

\section{The utilization of a spacer when using MDI in-line with ventilator circuits}

More than two decades ago, Rau et al. found that using a spacer with an MDI to deliver albuterol was more efficient than using a T-adapter to place MDI in-line during invasive ventilation directly (14). This finding has since been widely confirmed $(15,16,36)$. However, in our study, only 1 of 16 patients were treated with an MDI and a spacer; 
this finding was consistent with our previous national survey (37), which was implemented 8 years ago. A spacer chamber for $\mathrm{pMDI}$ delivery with an MDI for in-line aerosol delivery for ventilated patients in Chinese markets was not widely available, and this shortage might still exist today.

\section{The need to turn off humidifiers during aerosol therapy}

Previous studies have reported that humidification during invasive ventilation reduced aerosol delivery to the airways (4,11-13,36), with some researchers suggesting that the humidifier should be turned off during aerosol delivery. However, two recent randomized control trials demonstrated that there were no significant differences in lung deposition and clinical outcomes (38,39). Moreover, dry gas might cause airway irritation, mucus plug, and airway membrane injury. Therefore, turning off the humidifier should be avoided (40). However, $8.2 \%$ of patients in our study still received aerosol treatments with dry gas, even though it was clearly stated in the clinical consensus created by the Respiratory Care Committee of the Chinese Thoracic Society (26). Additionally, AARC recommended removing HME during aerosol treatment to avoid HME to filter the aerosol (41); however, in our study, less than one-third of participants did so. More education and quality improvement projects are called for.

\section{Limitations}

Nevertheless, in contrast with Ehrmann et al.'s study (28), wherein data were collected through individual treatments, our data were collected for each patient. Our method was intended to avoid a potential bias with patients receiving a large number of repeated aerosol treatments rather than clinical practice trends with the individual patient. However, our approach meant that we could not reflect the changes in aerosol devices, medications, or delivery techniques during the study. However, none of the devices or delivery techniques in our study changed for the same patient, and only $3.75 \%$ (6/160) of patients changed medications during study, which should not significantly impact the results.

Like Ehrmann et al.'s study, this study lasted for 2 weeks and was implemented in summer, when there tend to be fewer respiratory patients than in winter $(42,43)$. The numbers of patients admitted to ICU due to communityacquired pneumonia or asthma have been reported to peak in winter $(43,44)$, thus our study may underestimate the use of aerosol therapy in those patient populations. This study was performed in mainland China, and the results may not extrapolate to other countries or regions.

In this study, we not only reported on the current practice of aerosol therapy but also found that there is a gap between the clinical practice and current optimal evidence in 28 Chinese ICUs. The clinical practice of aerosol therapy varied across the different ICUs, and only $36.3 \%$ of the patients received aerosol treatments under conditions consistent with the evidence of optimal aerosol delivery efficiency.

\section{Conclusions}

Aerosol therapy varies in different ICUs in mainland China, and only one-third of patients in our study received aerosol treatments under optimal aerosol delivery efficiency from the available published evidence. More education and quality improvement projects are warranted. Nebulization protocols with evidence-based guidelines and recommendations are highly recommended for individual ICUs with the availability of equipment, including aerosol devices and types of ventilators. Aerosol auxiliary devices, such as spacers, for mechanical ventilation are needed in the Chinese market.

\section{Acknowledgments}

We would like to thank Dr. Stephan Ehrmann for his generosity in sharing his questionnaire. We would like to thank Mengmeng Wu, Dehua He, Tinggan Fu, Fang Ni, Xu Tan, Guanghan Wu, Binhai Pan, Liucun Li, Haiyan Wang, Guilan Zeng, Zhong Ni, Wei Tan, Yajuan Zong, Lihua Chen, Ping Liu, Hao Qin, and Ping He for collecting data.

Funding: This work was supported by the National Science and Technology Major Project for Control and Prevention of Major Infectious Diseases of China [2017ZX10103004] for the elaboration of the e-CRF.

\section{Footnote}

Reporting Checklist: The authors have completed the STROBE reporting checklist. Available at http://dx.doi. org/10.21037/atm-20-1313

Data Sharing Statement: Available at http://dx.doi. org/10.21037/atm-20-1313

Conflicts of Interest: All authors have completed the ICMJE 
uniform disclosure form (available at http://dx.doi. org/10.21037/atm-20-1313). JBF is Chief Science Officer for Aerogen Pharma Corp and discloses relationships with Dance Biopharm. JL discloses to receive research funding from Fisher \& Paykel Healthcare Ltd and Rice Foundation. The other authors have no conflicts of interest to declare.

Ethical Statement: The authors are accountable for all aspects of the work in ensuring that questions related to the accuracy or integrity of any part of the work are appropriately investigated and resolved. It was registered on ClinicalTrials.gov (NCT03597334) and was conducted by the Respiratory Care Committee of the Chinese Thoracic Society. Recruitment advertisement was posted on the official social media (WeChat App, Tencent, Hangzhou, China) of the Respiratory Care Committee of the Chinese Thoracic Society and centers were enrolled voluntarily. The study was conducted in accordance with the Declaration of Helsinki (as revised in 2013). The study was approved by the ethics committee of the leading hospital (Peking University People's Hospital, IRB approval No. 2018PHB05801). Additional ethical approvals were gained at each participating institution if required by the participating hospital. Written informed consent was obtained from patients or legal surrogates in all participating ICUs.

Open Access Statement: This is an Open Access article distributed in accordance with the Creative Commons Attribution-NonCommercial-NoDerivs 4.0 International License (CC BY-NC-ND 4.0), which permits the noncommercial replication and distribution of the article with the strict proviso that no changes or edits are made and the original work is properly cited (including links to both the formal publication through the relevant DOI and the license). See: https://creativecommons.org/licenses/by-nc-nd/4.0/.

\section{References}

1. Dhand R. Inhaled Drug Therapy 2016: The Year in Review. Respir Care 2017;62:978-96.

2. Ari A. Aerosol Therapy in Pulmonary Critical Care. Respir Care 2015;60:858-74.

3. Dhanani J, Fraser JF, Chan HK, et al. Fundamentals of aerosol therapy in critical care. Crit Care 2016;20:269.

4. Ari A, Areabi H, Fink JB. Evaluation of aerosol generator devices at 3 locations in humidified and non-humidified circuits during adult mechanical ventilation. Respir Care 2010;55:837-44.
5. Berlinski A, Willis JR. Albuterol delivery by 4 different nebulizers placed in 4 different positions in a pediatric ventilator in vitro model. Respir Care 2013;58:1124-33.

6. Galindo-Filho VC, Ramos ME, Rattes CS, et al. Radioaerosol Pulmonary Deposition Using Mesh and Jet Nebulizers During Noninvasive Ventilation in Healthy Subjects. Respir Care 2015;60:1238-46.

7. Ari A, Atalay OT, Harwood R, et al. Influence of nebulizer type, position, and bias flow on aerosol drug delivery in simulated pediatric and adult lung models during mechanical ventilation. Respir Care 2010;55:845-51.

8. Chatmongkolchart S, Schettino GP, Dillman C, et al. In vitro evaluation of aerosol bronchodilator delivery during noninvasive positive pressure ventilation: effect of ventilator settings and nebulizer position. Crit Care Med 2002;30:2515-9.

9. Dugernier J, Reychler G, Wittebole X, et al. Aerosol delivery with two ventilation modes during mechanical ventilation: a randomized study. Ann Intensive Care 2016;6:73.

10. Dugernier J, Wittebole X, Roeseler J, et al. Influence of inspiratory flow pattern and nebulizer position on aerosol delivery with a vibrating-mesh nebulizer during invasive mechanical ventilation: an in vitro analysis. J Aerosol Med Pulm Drug Deliv 2015;28:229-36.

11. Fink JB, Dhand R, Duarte AG, et al. Aerosol delivery from a metered-dose inhaler during mechanical ventilation. An in vitro model. Am J Respir Crit Care Med 1996;154:382-7.

12. Fink JB, Dhand R, Grychowski J, et al. Reconciling in vitro and in vivo measurements of aerosol delivery from a metered-dose inhaler during mechanical ventilation and defining efficiency-enhancing factors. Am J Respir Crit Care Med 1999;159:63-8.

13. Miller DD, Amin MM, Palmer LB, et al. Aerosol delivery and modern mechanical ventilation: in vitro/in vivo evaluation. Am J Respir Crit Care Med 2003;168:1205-9.

14. Rau JL, Harwood RJ, Groff JL. Evaluation of a Reservoir Device for Metered-Dose Bronchodilator Delivery to Intubated Adults. Chest 1992;102:924-30.

15. Boukhettala $N$, Poree $T$, Diot $P$, et al. In vitro performance of spacers for aerosol delivery during adult mechanical ventilation. J Aerosol Med Pulm Drug Deliv 2015;28:130-6.

16. Fuller HD, Dolovich MB, Turpie FH, et al. Efficiency of Bronchodilator Aerosol Delivery to the Lungs From the Metered Dose Inhaler in Mechanically Ventilated 
Patients. Chest 1994;105:214-8.

17. Ehrmann S, Lyazidi A, Louis B, et al. Ventilatorintegrated jet nebulization systems: tidal volume control and efficiency of synchronization. Respir Care 2014;59:1508-16.

18. Michotte JB, Staderini E, Le PD, et al. In Vitro Comparison of a Vibrating Mesh Nebulizer Operating in Inspiratory Synchronized and Continuous Nebulization Modes During Noninvasive Ventilation. J Aerosol Med Pulm Drug Deliv 2016;29:328-36.

19. Wan GH, Lin HL, Fink JB, et al. In vitro evaluation of aerosol delivery by different nebulization modes in pediatric and adult mechanical ventilators. Respir Care 2014;59:1494-500.

20. Dhand R, Tobin MJ. Bronchodilator delivery with metered-dose inhalers in mechanically-ventilated patients. Eur Respir J 1996;9:585-95.

21. Dhand R. How Should Aerosols Be Delivered During Invasive Mechanical Ventilation? Respir Care 2017;62:1343-67.

22. Kacmarek RM, Stoller JK, Heuer AJ. Egan's Fundamental of Respiratory Care. 11 ed. ELSEVIER; 2016.

23. Ehrmann S, Roche-Campo F, Sferrazza Papa GF, et al. Aerosol therapy during mechanical ventilation: an international survey. Intensive Care Med 2013;39:1048-56.

24. Zhu Z, Zheng J, Wu Z, et al. Clinical practice of nebulized therapy in China: a national questionnaire survey. J Aerosol Med Pulm Drug Deliv 2014;27:386-91.

25. Chinese Thoracic Society Respiratory Care Committee. Consensus statement on aerosol therapy Chin J Tubere Respir Dis 2014;37:805-8.

26. Chinese Thoracic Society Respiratory Care Committee. Aerosol therapy during mechanical ventilation consensus statement. Chin J Tubere Respir Dis 2014;37:812-5.

27. Zhang Z, Xu P, Fang Q, et al. Practice pattern of aerosol therapy among patients undergoing mechanical ventilation in mainland China: A web-based survey involving 447 hospitals. PLoS One 2019;14:e0221577.

28. Ehrmann S, Roche-Campo F, Bodet-Contentin L, et al. Aerosol therapy in intensive and intermediate care units: prospective observation of 2808 critically ill patients. Intensive Care Med 2016;42:192-201.

29. Dhand R. Aerosol delivery during mechanical ventilation: from basic techniques to new devices. J Aerosol Med Pulm Drug Deliv 2008;21:45-60.

30. Guellec SL, Mercier E, Chantrel G, et al. Influence of jet nebulization on ventilatory parameters during mechanical ventilation. Rev Mal Respir 2007;24:1241.
31. Velasco J, Berlinski A. Albuterol Delivery Efficiency in a Pediatric Model of Noninvasive Ventilation With Double-Limb Circuit. Respir Care 2018;63:141-6.

32. Abdelrahim ME, Paul P, Henry C. In-vitro characterisation of the nebulised dose during noninvasive ventilation. J Pharm Pharmacol 2010;62:966-72.

33. Michotte JB, Jossen E, Roeseler J, et al. In vitro comparison of five nebulizers during noninvasive ventilation: analysis of inhaled and lost doses. J Aerosol Med Pulm Drug Deliv 2014;27:430-40.

34. Berlinski A, Velasco J. Albuterol Delivery Efficiency in a Pediatric Model of Noninvasive Ventilation With a Single-Limb Circuit. Respir Care 2019;64:1366-70.

35. Galindo Filho VC, Alcoforado L, Rattes CS, et al. A mesh nebulizer is more effective than jet nebulizer to nebulize bronchodilators during non-invasive ventilation of subjects with COPD: A randomized controlled trial with radiolabeled aerosols. Respir Med 2019;153:60-7.

36. Diot P, Morra L, Smaldone GC. Albuterol delivery in a model of mechanical ventilation. Comparison of metered-dose inhaler and nebulizer efficiency. Am J Respir Crit Care Med 1995;152:1391-4.

37. Li J, Zhan Q, Liang Z, et al. Respiratory Care Practices and Requirement for Respiratory Therapists in Beijing ICUs. Respir Care 2012;57:370-6.

38. Moustafa IOF, Ali MRA, Al Hallag M, et al. Lung deposition and systemic bioavailability of different aerosol devices with and without humidification in mechanically ventilated patients. Heart Lung 2017;46:464-7.

39. Moustafa IOF, ElHansy MHE, Al Hallag M, et al. Clinical outcome associated with the use of different inhalation method with and without humidification in asthmatic mechanically ventilated patients. Pulm Pharmacol Ther 2017;45:40-6.

40. Lin H-L, Fink JB, Zhou Y, et al. Influence of moisture accumulation in inline spacer on delivery of aerosol using metered-dose inhaler during mechanical ventilation. Respir Care 2009;54:1336-41.

41. Restrepo RD, Walsh BK. Humidification during invasive and noninvasive mechanical ventilation: 2012. Respir Care 2012;57:782-8.

42. Olofsson S, Brittain-Long R, Andersson LM, et al. PCR for detection of respiratory viruses: seasonal variations of virus infections. Expert Rev Anti Infect Ther 2011;9:615-26.

43. Pendergraft TB, Stanford RH, Beasley R, et al. Seasonal variation in asthma-related hospital and intensive care unit admissions. J Asthma 2005;42:265-71. 
44. Dodek PM, Monica N, Keenan SP, et al. Intensive care unit admissions for community-acquired pneumonia are seasonal but are not associated with weather or reports of influenza-like illness in the community. J Crit Care

Cite this article as: Lyu S, Li J, Yang L, Du X, Liu X, Chuan L, Jing G, Wang Z, Shu W, Ye C, Dong Q, Duan J, Fink JB, Gao Z, Liang Z, on behalf of Respiratory Care Committee in Chinese Thoracic Society. The utilization of aerosol therapy in mechanical ventilation patients: a prospective multicenter observational cohort study and a review of the current evidence. Ann Transl Med 2020;8(17):1071. doi: 10.21037/atm-20-1313
2011;26:228-33.

(English Language Editors: J. Chapnick and J. Reynolds) 
Supplementary

Appendix 1 The investigators and centers in this study

\begin{tabular}{|c|c|}
\hline Investigator & Centers \\
\hline Guoqiang Jing & Department of Respiratory and Critical Care Medicine, Binzhou Medical University Hospital \\
\hline Qionglan Dong & Department of Critical Care Medicine, The Third People's Hospital of Mianyang \\
\hline Mengmeng Wu & Department of Critical Care Medicine, Binzhou People's Hospital \\
\hline Weiwei Shu & Department of Critical Care Medicine, Yongchuan Hospital of Chongqing Medical University \\
\hline Lihua Chen & Department of Critical Care Medicine, Gansu Second Provincial People's Hospital \\
\hline Ping Liu & Department of Critical Care Medicine, the Seventh Affiliated Hospital, Sun Yat-sen University \\
\hline Zhenyan Wang & Department of Critical Care Medicine, Peking University International Hospital \\
\hline Chunjuan Ye & Department of Surgical Intensive Care Unit, the First Affiliated Hospital of Xi'an Jiaotong University \\
\hline Wei Tan & Department of Respiratory and Critical Care Medicine, the First Hospital of China Medical University \\
\hline Hao Qin & Department of Respiratory and Critical Care Medicine, Shanghai Changhai Hospital \\
\hline Jun Duan & Department of Respiratory and Critical Care Medicine, the First Affiliated Hospital of Chongqing Medical University \\
\hline Liucun Li & Department of Respiratory and Critical Care Medicine, the Second Xiangya Hospital of Central South University \\
\hline Binhai Pan & Department of Respiratory and Critical Care Medicine, Jinling Hospital \\
\hline Xiaoyi Liu & Department of Critical Care Medicine, Dazhou Central Hospital \\
\hline Xu Tan & $\begin{array}{l}\text { Department of Respiratory and Critical Care Medicine, Union Hospital Affiliated with Tongji Medical College of } \\
\text { Huazhong University of Science and technology }\end{array}$ \\
\hline Tinggan Fu & Department of Surgical Intensive Care Unit, the First Affiliated Hospital, Sun Yat-sen University \\
\hline Yajuan Zong & Department of Critical Care Medicine, Yixing No. 2 People's Hospital \\
\hline Guilan Zeng & Department of Critical Care Medicine, Zhangzhou Hospital Traditional Chinese Medicine \\
\hline Ping He & Department of Cardiac Surgery, Southwest Hospital, the First Hospital Affiliated to Army Medical University \\
\hline Fang $\mathrm{Ni}$ & Department of Respiratory and Critical Care Medicine, the Central Hospital of Wuhan \\
\hline
\end{tabular}


Table S1 Studies compared aerosol delivery via continuous jet and vibrating mesh nebulizer in invasive ventilated patients with humidification and bias flow

\begin{tabular}{|c|c|c|c|c|c|c|c|c|c|}
\hline \multirow{2}{*}{ Author, year } & \multirow{2}{*}{ Study type } & \multirow{2}{*}{ Population } & \multirow{2}{*}{ Ventilator setting } & \multicolumn{3}{|c|}{ Inhaled dose of continuous jet nebulizer } & \multicolumn{3}{|c|}{ Inhaled dose of vibrating mesh nebulizer } \\
\hline & & & & Before Y-piece & Inlet to humidifier & $\mathrm{P}$ & Before Y-piece & Inlet to humidifier & $\mathrm{P}$ \\
\hline Ari, 2010 (7) & In vitro & Adult & Vt 500 mL, PEEP 5, f 20 & $4.0 \% \pm 0.1 \%$ & $4.7 \% \pm 0.4 \%$ & & $9.7 \% \pm 0.6 \%$ & $21.4 \% \pm 0.4 \%$ & 0.001 \\
\hline Ari, 2010 (7) & In vitro & Pediatric & Vt 100 mL, PEEP 5, f 20 & $3.8 \% \pm 0.3 \%$ & $4.1 \% \pm 0.4 \%$ & & $8.4 \% \pm 0.2 \%$ & $10.6 \% \pm 0.3 \%$ & 0.01 \\
\hline Berlinski, 2015 (45) & & & & $102 \pm 7 \mu \mathrm{g}$ & $218 \pm 41 \mu \mathrm{g}$ & $<0.02$ & $184 \pm 29 \mu \mathrm{g}$ & $238 \pm 128 \mu \mathrm{g}$ & 0.36 \\
\hline Berlinski, 2013 (5) & & & Vt 200 mL, PEEP 5, f 20 & $2.0 \% \pm 0.1 \%$ & $5.4 \% \pm 0.6 \%$ & $<0.01$ & $8.7 \% \pm 2.5 \%$ & $28.5 \% \pm 8.6 \%$ & $<0.01$ \\
\hline Berlinski, 2015 (45) & & & & $90 \pm 17 \mu g$ & $230 \pm 38 \mu \mathrm{g}$ & $<0.02$ & $123 \pm 17 \mu \mathrm{g}$ & $326 \pm 96 \mu \mathrm{g}$ & $<0.03$ \\
\hline
\end{tabular}

Table S2 Studies compared aerosol delivery via continuous jet and vibrating mesh nebulizer in noninvasive ventilated patients with single limb ventilator

\begin{tabular}{|c|c|c|c|c|c|c|c|c|c|}
\hline \multirow[b]{2}{*}{ Author, year } & \multirow[b]{2}{*}{ Study type } & \multirow[b]{2}{*}{ Population } & \multirow{2}{*}{$\begin{array}{l}\text { Ventilator } \\
\text { setting }\end{array}$} & \multicolumn{3}{|c|}{ Inhaled dose of continuous jet nebulizer } & \multicolumn{3}{|c|}{ Inhaled dose of vibrating mesh nebulizer } \\
\hline & & & & $\begin{array}{l}\text { Placed between exhalation port } \\
\text { and mask }\end{array}$ & $\begin{array}{l}\text { Placed between exhalation } \\
\text { port and ventilator }\end{array}$ & $P$ & $\begin{array}{l}\text { Placed between exhalation } \\
\text { port and mask }\end{array}$ & $\begin{array}{l}\text { Placed between exhalation } \\
\text { port and ventilator }\end{array}$ & $P$ \\
\hline Michotte, 2016 (18) & In vitro & Adult & $\begin{array}{l}\text { IPAP 15, EPAP } \\
5\end{array}$ & & & & $115 \pm 1 \mathrm{mg}$ & $31 \pm 1 \mathrm{mg}$ & $<0.001$ \\
\hline Chatmongkolchart, 2002 (8) & & & IPAP 20, EPAP & $24.5 \% \pm 1.3 \%$ & $5.2 \% \pm 0.4 \%$ & $<0.001$ & & & \\
\hline Calvert, 2006 (46) & & & 5 & $544 \pm 85 \mu g$ & $647 \pm 67 \mu g$ & $>0.05$ & & & \\
\hline Abdelrahim, 2010 (32) & & & & $1207.2 \pm 161.3 \mu \mathrm{g}$ & $341 \pm 69.5 \mu \mathrm{g}$ & $<0.001$ & $2572.5 \pm 150.9 \mu \mathrm{g}$ & $935.5 \pm 273.3 \mu \mathrm{g}$ & $<0.001$ \\
\hline Michotte, 2014 (33) & & & & $61.2 \pm 3.6 \mathrm{mg}$ & $46.2 \pm 5.3 \mathrm{mg}$ & $<0.05$ & $221.1 \pm 5.1 \mathrm{mg}$ & $70.1 \pm 6.3 \mathrm{mg}$ & $<0.001$ \\
\hline Berlinski, 2019 (34) & & Pediatric & & $5.9 \%$ & $0.9 \%$ & $<0.001$ & $14.9 \%$ & $4.3 \%$ & $<0.001$ \\
\hline Dai, 2014 (47) & In vitro & Adult & IPAP 25, EPAP & $24.18 \% \pm 1.08 \%$ & $22.23 \% \pm 0.79 \%$ & $<0.05$ & & & \\
\hline Peng, 2018 (48) & & & 5 & $17.66 \% \pm 0.83 \%$ & $16.16 \% \pm 1.90 \%$ & & & & \\
\hline
\end{tabular}

Table S3 Studies compared aerosol delivery via continuous jet and vibrating mesh nebulizer in noninvasive ventilated patients with dual limb ventilator

\begin{tabular}{|c|c|c|c|c|c|c|c|c|c|c|c|}
\hline \multirow[b]{2}{*}{ Author, year } & \multirow[b]{2}{*}{ Study type } & \multirow[b]{2}{*}{ Population } & \multirow[b]{2}{*}{ Ventilator setting } & \multicolumn{4}{|c|}{ Inhaled dose of continuous jet nebulizer } & \multicolumn{4}{|c|}{ Inhaled dose of vibrating mesh nebulizer } \\
\hline & & & & $\begin{array}{c}\text { Placed between Y-piece } \\
\text { and mask }\end{array}$ & $\begin{array}{l}\text { Placed before } \\
\text { Y-piece }\end{array}$ & Inlet to humidifier & $\mathrm{P}$ & $\begin{array}{c}\text { Placed between Y-piece } \\
\text { and mask }\end{array}$ & $\begin{array}{l}\text { Placed before } \\
\text { Y-piece }\end{array}$ & Inlet to humidifier & $P$ \\
\hline Velasco, $2018(31)$ & In vitro & Pediatric & IPAP 20, EPAP 5 & & $3.8 \%$ & $3.5 \%$ & & & $17.6 \%$ & $13.3 \%$ & 0.01 \\
\hline $\begin{array}{l}\text { Bodet-Contentin, } \\
2019 \text { (49) }\end{array}$ & In vitro & Adult & IPAP 15, EPAP 5 & & & & & $729 \pm 61 \mu \mathrm{g}$ & $555 \pm 44 \mu \mathrm{g}$ & & \\
\hline
\end{tabular}




\section{References}

45. Berlinski A, Willis JR. Effect of tidal volume and nebulizer type and position on albuterol delivery in a pediatric model of mechanical ventilation. Respir Care 2015;60:1424-30.

46. Calvert LD, Jackson JM, White JA, et al. Enhanced delivery of nebulised salbutamol during non-invasive ventilation. J Pharm Pharmacol 2006;58:1553-7.

47. Dai B, Kang J, Sun LF, et al. Influence of exhalation valve and nebulizer position on albuterol delivery during noninvasive positive pressure ventilation. J Aerosol Med
Pulm Drug Deliv 2014;27:125-32.

48. Peng Y, Dai B, Hu CX, et al. Which nebulizer position should be avoided? An extended study of aerosol delivery and ventilator performance during noninvasive positive pressure ventilation. Respiration 2018;95:145-53.

49. Bodet-Contentin L, Guillon A, Boulain T, et al.

Salbutamol nebulization during noninvasive ventilation in exacerbated chronic obstructive pulmonary disease patients: a randomized controlled trial. J Aerosol Med Pulm Drug Deliv 2019;32:149-55. 